\title{
Prevalence and determinants of unmet need for contraception in North Gonja District, Ghana
}

\author{
Anthony Wemakor ${ }^{*}$ (D, Humphrey Garti, Nawaf Saeed, Obed Asumadu and Bede Anyoka
}

\begin{abstract}
Background: Unmet need for contraception contributes to the burden of unwanted pregnancies, which are correlated with a host of adverse maternal and child outcomes. The aim of this study was to determine the prevalence and identify the determinants of unmet need for contraception in North Gonja District, Ghana.
\end{abstract}

Methods: A cross-sectional survey involving 386 randomly selected women of childbearing age was conducted in North Gonja district, Ghana, with the use of a questionnaire in household interviews. Women were classified as having unmet need for contraception if they were fecund, sexually active and wished to postpone the next birth or halt childbearing completely but were not using any form of contraception. Chi-square/Fisher's exact test and logistic regression analysis were used to identify the determinants of unmet need.

Results: The mean age of the study population was 26.1 ( \pm 8.4 ) years and awareness on contraception was almost universal in the district (95.9\%). The overall prevalence of unmet need for contraception was $38.9 \%$, with $27.5 \%$ having unmet need for limiting and 12.2\% unmet need for spacing. In multivariate analysis, compared to women aged 25-29years, those aged 20-24 years [Adjusted Odds Ratio (AOR) 0.26; 95\% Confidence Interval (CI) 0.11-0.58] and 30 years and above (AOR $0.25 ; 95 \% \mathrm{Cl} 0.09-0.73$ ) were less likely to have unmet need for contraception. However, uneducated women (AOR 5.06; 95\% Cl 1.07-24.01) compared with those educated to tertiary level; those unaware of family planning (AOR 3.93; 95\% Cl 1.12-13.80) compared to those aware; and those who had not previously practised contraception (AOR $1.81 ; 95 \% \mathrm{Cl} 1.09-3.00$ ) compared to those who did were more likely to have unmet need.

Conclusions: The present study found high prevalence of both awareness on and unmet need for contraception among the study population. Unmet need for contraception is associated with age, educational status, awareness on family planning and previous contraception practice. Educational campaigns to promote contraception should prioritize women of middle age and low educational status. Further studies are needed to understand the low correlation between awareness on and unmet need for contraception.

Keywords: Contraception, family planning, unmet need, North Gonja, Ghana

\footnotetext{
* Correspondence: anthonywemakor@yahoo.com

School of Allied Health Sciences, University for Development Studies, Tamale, Ghana 


\section{Background}

Pregnancy and childbirth are important causes of mortality among women of reproductive age, especially in low resource settings [1]. About half of all pregnancies are unplanned [2], which contributes significantly to maternal mortality burden [3]. Maternal health is an issue of concern globally and is highlighted in the third Sustainable Development Goal that aims to reduce maternal mortality ratio globally to not more than 70 maternal deaths per 100,000 live births by 2030 [4]. Unmet need for contraception is of great significance given that approximately $29 \%$ of maternal deaths could be prevented through met need for contraception [5]. Unmet need for contraception refers to the percentage of fecund (do not meet the criteria for infecundity) and sexually active women (married or in a union) of reproductive age who wish to postpone the next birth for at least 2 years or halt child bearing completely but are not using any form of contraception [6]. The 2012 London Summit on Family Planning (FP) called for increased investments in programmes to minimize unintended pregnancies worldwide and set a goal of satisfying the unmet need for FP of 150 million additional women by 2020 [7].

In Western Africa, only one in four women of reproductive age used a modern method of contraception in 2012 and modern contraceptive use was considerably low in many countries of the sub-region [8]. SubSaharan Africa had the highest level of unmet need for contraception in 2010 (25\%). Out of 35 countries, 24 had unmet need prevalence rate of more than $20 \%$ and 7 of these had rates above $30 \%$ in 2011 [9]. The recent Ghana Demographic and Health Survey estimated the level of unmet need for contraception for married women in Ghana to be $30 \%$ but it varies with age, region of residence, educational status and household wealth index [10]. Unmet need is highest among teenagers (1519 years) $(50.7 \%)$ but lowest in older women (45-49 years) (14.2\%), comparatively higher in Volta and Eastern Regions (above 35.0\%), and lowest in women with at least secondary education $(24.1 \%)$ or those in the richest wealth quintile (25.3\%). Some of the reasons why women do not use a contraceptive method are: lack of knowledge on contraceptive usage [11], concerns about health [11], side effects of contraceptives [12], behavioural requirements and objections from husbands [13].

In Ghana, health care delivery is provided by both public and private sectors with the Ministry of Health having oversight responsibility over the whole health system. The country has a three-tier decentralized health system consisting of district (primary), regional (secondary), and national (tertiary) levels. Health services are provided largely by Ghana Health Service, Teaching Hospitals and faith-based, quasi- and non-governmental health facilities [14]. All forms of modern contraceptives
(IUDs, implants, injectables, oral contraceptive pills and condoms) are distributed at highly subsidized rates by hospitals, clinics, health centres and community-based health planning and services compounds. Other distribution outlets are pharmacies, over the counter medicine sellers and community health volunteers for rural communities.

The prevalence of unmet need for FP is highest in low and middle income countries including Ghana [15] but very little is known about its determinants. Similarly, there is very scanty data on the level of unmet need and its determinants in North Gonja District hampering the planning and delivery of FP services. Thus, investigating the underlying causes of unmet need for modern contraception in North Gonja is critical for improving the health of mothers and babies in the district. The aim of the present study was therefore to determine the prevalence and determinants of unmet need for contraception in North Gonja District, Ghana.

\section{Methods \\ Study design, area and population}

The study was a cross-sectional survey conducted in North Gonja District in March to June, 2016. The North Gonja District is located in the western part of Savanna Region and lies within longitude 1051 and 20,581 West and latitude 80,321 and 10,021 North. The district shares boundaries to the West with West Gonja and Wa East districts, to the East with Tolon District, to the North with Mamprugu-Moagduri and Kumbungu districts and to the South with Central Gonja district [16]. The district has a total land mass of about $4845.5 \mathrm{sq} \mathrm{km}$, representing about $6.9 \%$ of the total land size of the Region. About $75 \%$ of the communities in the district are difficult to access due to the poor nature of the road network and heavy flood during rainy season. This normally affects the delivery of health services in the district. The inhabitants of the district are predominantly Gonjas and Tamplumas but people of other ethnic groups such as Dagomba, Mamprusi, Hanga and Ewe can also be found there.

The District is divided into four health sector operational sub-districts namely Bawena, Daboya, Lingbinsi and Mankarigu and has a total of sixty-one (61) communities. The district has an estimated population of 43,547 [16]. The study population consisted of women aged 15-45 years in the district.

\section{Sample size and sampling}

A minimum sample size of 384 was derived using the formula $\mathrm{N}=\left[\mathrm{z}^{2} \mathrm{p}(1-\mathrm{p})\right] \div \mathrm{ME}^{2}$ [17], where $\mathrm{z}=$ confidence interval at 95\% thus 1.96; $\mathrm{p}=$ assumed prevalence of unmet need for contraception in North Gonja District, Ghana, 50\%; and $\mathrm{ME}=$ margin of error, 0.05 . The 
sample size was rounded up to 386 . Convenience sampling was used to select one sub-district (Daboya) out of the 4 sub-districts in the District because of the relative ease of access and 20 communities were also conveniently selected from this sub-district. Probability proportional to size was used to determine the number of women to sample from each of the selected communities. The respondent women were selected using simple random sampling. Four hundred women were approached to get the 386 women to interview giving a response rate of $96.5 \%$. The 14 women not interviewed were not resident in the study area $(n=7)$, did not consent to participate $(n=5)$ and could not be interviewed because of language barrier $(n=2)$.

\section{Data collection}

Data were collected in face-to-face interviews in respondents' homes by 4 trained community health nurses who were engaged in the provision of reproductive health services at their work places. The questionnaire used had sections on socio-demographic characteristics, reproductive and fertility history, and knowledge and practice of FP (See Additional file 1). The socio-demographic characteristics included age, highest educational status, marital status, occupation, and religious afilliation. Age in years was self-reported and this was categorised into 5-year groups (i.e., < 20 years, 20-24 years); marital status was categorized into married, and single or divorced (i.e., not currently married); and highest educational level ranged from no education to tertiary level education. Ethnicity had two main categories Gonja and Dagomba and all others were grouped together as "others"; and religion had Muslim and "others". Information collected on reproduction and fertility history of respondents included age at first birth, number of children, previous contraceptive use, whether they would accept help in limiting/spacing childbirth and reasons for non-use of contraceptives. Issues explored on FP knowledge included what FP was and respondents were also asked to name at least one modern contraceptive.

\section{Study variables}

The dependent variable of the study was unmet need for modern contraception and the independent variables were socio-demographic factors, and contraceptive knowledge and practices of the women.

\section{Unmet need for limiting childbirth}

The proportion of fecund, sexually active women who wish to stop childbearing completely but are not using any modern contraceptive method.

\section{Unmet need for spacing childbirth}

The proportion of fecund, sexually active women who want another child after 2 years but are not using any modern contraceptive method.

\section{Unmet need for modern contraception}

Any woman having unmet need for limiting or spacing childbirth was considered as having unmet need for contraception [6].

Women were considered to be fecund if they were pregnant or postpartum amenorrheic. Non-pregnant and non-amenorrheic women were classified as fecund if they did not meet the criteria for infecundity i.e., they were married for at least 5 years but did not have a birth in the past 5 years or are not currently pregnant and have never used any contraceptive method; or selfreported infecundity, hysterectomy, or menopause or never menstruated or have been postpartum amenorrheic for at least 5 years; or they are not pregnant or amenorrheic and their last menstrual period occurred more than 6 months prior to the survey. All married women were considered to be sexually active and unmarried women were considered to be sexually active if they had a sexual encounter in the month preceding the survey [6].

\section{Quality control}

The interviewers underwent a 2-day training on the contents of the questionnaire and techniques of questionnaire administration. Prior to data collection, the questionnaire was pretested in a community in the North Gonja district that was not part of the study communities and questions that were unambigous or did not elicit the appropriate responses were rephrased.

\section{Data management and analysis}

Data management and analysis were performed using Stata (version 13, Stata Corporation, College Station, Texas, USA). The determinants of unmet for contraception were identified in a two-stage process. Bivariate associations between unmet need for contraception and the characteristics of the women were explored using Chi-square or Fisher's exact test and those characteristics that were statistically significant were retained and entered into a logistic regression model. In the logistic regression analysis, odds ratios and their 95\% confidence intervals were computed to reflect the strength of association between unmet need and its independent determinants. In all analyses, a $p$-value less than 0.05 was considered statistically significant.

\section{Ethics approval and consent to participate}

The protocol for this study (Protocol Number 04-2016) was approved by the Joint Ethics Board of School of 
Medicine and Health Sciences and School of Allied Health Sciences, University for Development Studies, Tamale. Written informed consent was obtained from the study women and from the parents of subjects less than 16 years old before interviews were conducted. It was made clear to all subjects that participation was voluntary.

\section{Results}

\section{Socio-demographic data of respondents}

Majority of our sample were within 20-24 years age group (Table 1$)$ with an average age of $26.1( \pm 8.4)$ years. The majority were married $(64.5 \%)$ while a greater majority were Muslims (74.1\%) and belonged to Gonja $(83.7 \%)$, which is the predominant tribe in the study area. With respect to occupation and education, most of

Table 1 Socio-demographic data of respondents $(n=386)$

\begin{tabular}{|c|c|c|}
\hline Variable & Frequency & Percent \\
\hline \multicolumn{3}{|l|}{ Age group (years) } \\
\hline$<20$ & 81 & 21.0 \\
\hline $20-24$ & 100 & 25.9 \\
\hline $25-29$ & 70 & 18.1 \\
\hline $30-34$ & 95 & 24.6 \\
\hline $35+$ & 40 & 10.4 \\
\hline \multicolumn{3}{|l|}{ Religion } \\
\hline Muslim & 286 & 74.1 \\
\hline Others & 100 & 25.9 \\
\hline \multicolumn{3}{|l|}{ Educational level } \\
\hline None & 76 & 19.7 \\
\hline Primary & 22 & 5.7 \\
\hline Junior High School & 143 & 37.0 \\
\hline Senior High School & 112 & 29.0 \\
\hline Tertiary & 33 & 8.5 \\
\hline \multicolumn{3}{|l|}{ Ethnicity } \\
\hline Gonja & 323 & 83.7 \\
\hline Dagomba & 42 & 10.9 \\
\hline Others & 21 & 5.4 \\
\hline \multicolumn{3}{|l|}{ Marital status } \\
\hline Married & 249 & 64.5 \\
\hline Single or Divorced & 137 & 35.5 \\
\hline \multicolumn{3}{|l|}{ Occupation } \\
\hline Farmer & 38 & 9.8 \\
\hline Trader & 177 & 45.9 \\
\hline Civil/Public Servant & 17 & 4.1 \\
\hline Student & 76 & 19.7 \\
\hline Unemployed & 54 & 14.0 \\
\hline Others & 24 & 6.5 \\
\hline
\end{tabular}

them $(45.9 \%)$ were traders and had education up to Junior High School level (37.0\%).

\section{Contraception knowledge and practice of the women}

We collected information on contraception knowledge and practice of women. Our results show that, awareness on FP among our study population was almost universal. A greater majority of the women (95.9\%) were aware of FP and had ever used a modern method or did something to prevent pregnancy $(54.1 \%)$ as depicted in Table 2. Nevertheless, more than half of them (53.4\%) had never used a modern FP method and a large proportion of them $(73.6 \%)$ would accept any help to avoid

Table 2 Contraception knowledge and practice of the women

\begin{tabular}{lll}
\hline Characteristic & Frequency & Percent \\
\hline Awareness on family planning & & \\
Yes & 370 & 95.9 \\
No & 16 & 4.1
\end{tabular}

Had ever used a method or did something to prevent pregnancy

$\begin{array}{lll}\text { Yes } & 209 & 54.1 \\ \text { No } & 177 & 45.9\end{array}$

Had ever used a modern family planning method

$\begin{array}{lll}\text { Yes } & 180 & 46.6\end{array}$

No $206 \quad 53.4$

Would accept any help to avoid getting pregnant

$\begin{array}{lll}\text { Yes } & 284 & 73.6\end{array}$

$\begin{array}{lll}\text { No } & 102 & 26.4\end{array}$

Reasons for not using modern contraceptives

Unmarried status and fertility-related reasons $(n=115)$

$\begin{array}{lll}\text { Not married } & 22 & 19.1 \\ \text { Not having sex } & 58 & 50.4 \\ \text { Infrequent sex } & 18 & 15.7 \\ \text { Menopausal/hysterectomy } & 8 & 7.0 \\ \text { Sub-fecund/infecund } & 5 & 4.4 \\ \text { Lactational amenorrhea } & 2 & 1.7 \\ \text { Breastfeeding } & 2 & 1.7 \\ \text { ethod-related reasons }(\boldsymbol{n}=\mathbf{7 8}) & & \\ \text { Health concerns } & 11 & 14.1 \\ \text { Fear of side effects } & 49 & 62.8 \\ \text { Lack of access to contraceptives } & 2 & 2.6 \\ \text { Other reasons } & 16 & 20.5\end{array}$

Opposition to use and lack of knowledge reasons $(n=59)$

$\begin{array}{lll}\text { Respondent opposed } & 6 & 10.2\end{array}$

Husband/partner opposed $\quad 33 \quad 55.9$

$\begin{array}{lll}\text { Others opposed } & 14 & 23.7\end{array}$

Religious prohibition $\quad 5.5$

Respondent knows no method $\quad 1 \quad 1.7$ 
getting pregnant. On the reasons for lack of use of modern contraceptives, $29.8 \%$ were not using because they were not married or because of fertility-related reasons, $20.2 \%$ gave method-related reasons, and $15.3 \%$ gave reasons such as opposition to use by self or significant others. About half (50.4\%) of those who cited unmarried status and fertility reasons attributed non-use of modern contraceptives to not having sex, $62.8 \%$ of those who gave method related-reasons attribute non-use to fear of side effects, and $55.9 \%$ of those who cited opposition to use reasons attributed non-use to opposition from husband/partner.

\section{Prevalence and determinants of unmet need for contraception}

The overall prevalence of unmet need for contraception in the north Gonja District was $38.9 \%$, with $27.5 \%$ having unmet need for limiting and $12.2 \%$ unmet need for spacing childbirth. Unadjusted or bivariate analyses revealed that six variables: age $(p<0.001)$, educational status $(\mathrm{p}<0.001)$, occupation $(\mathrm{p}<0.001)$, awareness on FP $(p=0.048)$, experience with pregnancy prevention in the past $(\mathrm{p}<0.001)$ and previous use of modern contraceptives $(\mathrm{p}<0.001)$ were statistically significantly associated with unmet need for contraception (Table 3). Following multivariate logistic regression analysis, age, educational status, awareness on FP and previous use of any form of contraception remained as independent determinants of unmet need for contraception. Compared to women aged 25-29 years, women aged 20-24 years and those aged 30 years and above were about $75 \%$ less likely to have unmet need for contraception [Adjusted Odds Ratio (AOR) 0.26; 95\% Confidence Interval (CI) 0.11-0.58; $p=0.001$; AOR 0.25; 95\% CI 0.09-0.73; $p=0.011$ ] (Table 4). Women with no formal education were five times more likely to have unmet need for contraception compared with those who had education up to tertiary level (AOR 5.06; 95\% CI 1.07$24.01 ; p=0.041$ ). Furthermore, it was found that, women who were unaware of FP were almost four times more likely to have unmet need (AOR 3.93; 95\% CI 1.12-13.80; $p=0.033$ ). Finally, women who had never used a modern contraception method nor did anything to prevent pregnancy before were about two times more likely to have unmet need for contraception (AOR 1.81; 95\% CI 1.093.00; $p=0.022$ ).

\section{Discussion}

The primary objective of the present study was to estimate the prevalence of unmet need for contraception and identify its associated factors in North Gonja District, Ghana. We found that $38.9 \%$ of our study women have overall unmet need for contraception with more women having unmet need for limiting than for spacing childbirth.
Awareness on FP was almost universal, a finding that is supported by the recent Demographic and Health Survey of Ghana and the United Nations report on world contraceptives $[10,18]$. The high awareness possibly reflects the outcome of the work done by both Governmental and Non-Governmental Organisations in promoting reproductive health education in the District and the easy accessibility of reproductive health information due to the Community-based Health Planning and Services compounds, a concept employed to bring health services to the door step of the rural poor in Ghana $[19,20]$.

Despite the high awareness on FP among women in the study, less than half of the population reported ever use of modern contraceptives culminating in a high prevalence of unmet need for contraception (38.9\%). Our prevalence is more than both the national and regional averages of 30 and $28 \%$ respectively [10] and the average for Sub-Saharan Africa (31.0\%) [21]. However, elsewhere in Africa, a few studies reported lower rates of unmet need (e.g., 16.2\% in Ethiopia in 2019 [22], but most studies tend to report higher rates i.e., $51.7 \%$ in Angola in 2018 [23], 52.4\% in Ethiopia in 2011 [24], and $44.8 \%$ in Sudan in 2013 [25]. The high prevalence of unmet need in the present study may be attributed to contraceptive security issues such as distribution problems, fear of side effects, unacceptability of contraception, perception of inability to conceive if contraception is stopped, lack of contraceptive information, opposition from husband to contraceptive use, inability to afford contraceptives, and unaddressed myths, rumours and misconceptions about contraception [12, 26-29]. Nevertheless, the high level of unmet need among these women is a cause for concern and reinforces the importance of improving FP programmes in order to promote contraception and prevent unwanted pregnancy and its attendant problems.

Following multivariate analysis, age, education level, awareness on FP and previous use of contraception were identified as the determinants of unmet need for contraception in the study population. With respect to age, we found that unmet need was less prevalent in younger or older women. A possible explanation for this may be perceived reduced risk of pregnancy due to infrequent sexual activity among younger and older women. Younger women may lack comprehensive education on FP, may not have the resources to access FP services or may be hindered by stigma [22] while older women may not be married or in union.

We found that uneducated women were more likely to have unmet need compared to those with tertiary level education. This finding shows that, women with higher educational status are more likely to use FP compared to their counterparts with no education or lower 
Table 3 Association between characteristics of women and unmet need for contraception status

\begin{tabular}{|c|c|c|c|c|}
\hline \multirow[t]{2}{*}{ Characteristic } & \multirow[t]{2}{*}{ Total } & \multicolumn{2}{|c|}{ Unmet need for contraception } & \multirow[t]{2}{*}{ Test statistics } \\
\hline & & No (\%) & Yes (\%) & \\
\hline \multicolumn{5}{|l|}{ Age group (years) } \\
\hline$<20$ & 81 & $42(51.9)$ & $39(48.1)$ & \multirow[t]{5}{*}{$X^{2}=32.286 ; p<0.001$} \\
\hline $20-24$ & 100 & $83(83.0)$ & $17(17.0)$ & \\
\hline $25-29$ & 70 & $41(58.6)$ & $29(41.4)$ & \\
\hline $30-34$ & 95 & $44(46.3)$ & $51(53.7)$ & \\
\hline $35+$ & 40 & $26(65.0)$ & $14(35.0)$ & \\
\hline \multicolumn{5}{|l|}{ Educational level } \\
\hline None & 76 & $32(42.1)$ & $44(57.9)$ & \multirow[t]{5}{*}{$X^{2}=19.985 ; p=0.001$} \\
\hline Primary & 22 & $17(77.3)$ & $5(22.7)$ & \\
\hline Junior High School & 143 & $86(60.1)$ & $57(39.9)$ & \\
\hline Senior High School & 112 & $75(67.0)$ & $37(33.0)$ & \\
\hline Tertiary & 33 & $26(78.8)$ & $7(21.2)$ & \\
\hline \multicolumn{5}{|l|}{ Religion } \\
\hline Muslim & 286 & $174(60.8)$ & $112(39.2)$ & \multirow[t]{2}{*}{$X^{2}=0.042 ; p=0.838$} \\
\hline Others & 100 & $62(62.0)$ & $38(38.0)$ & \\
\hline \multicolumn{5}{|l|}{ Ethnicity } \\
\hline Gonja & 323 & $192(59.4)$ & $131(40.6)$ & \multirow[t]{3}{*}{$X^{2}=3.234 ; p=0.198$} \\
\hline Dagomba & 42 & $31(73.8)$ & $11(26.2)$ & \\
\hline Others & 21 & $13(61.9)$ & $8(38.1)$ & \\
\hline \multicolumn{5}{|l|}{ Marital status } \\
\hline Married & 249 & $147(59.0)$ & $102(41.0)$ & \multirow[t]{2}{*}{$X^{2}=1.307 ; p=0.253$} \\
\hline Single or divorced & 137 & $89(65.0)$ & $48(35.0)$ & \\
\hline \multicolumn{5}{|l|}{ Occupation } \\
\hline Farmer & 38 & $14(36.8)$ & $24(63.2)$ & \multirow[t]{6}{*}{$p<0.001$} \\
\hline Trader & 177 & $109(61.6)$ & $68(38.4)$ & \\
\hline Civil/public servant & 17 & $13(76.5)$ & $4(23.5)$ & \\
\hline Student & 76 & $41(53.9)$ & $35(46.1)$ & \\
\hline Unemployed & 54 & $46(85.2)$ & $8(14.8)$ & \\
\hline Others & 24 & $13(54.2)$ & $11(45.8)$ & \\
\hline \multicolumn{5}{|c|}{ Awareness on family planning } \\
\hline Yes & 370 & $230(62.2)$ & $140(37.8)$ & \multirow[t]{2}{*}{$X^{2}=3.926 ; p=0.048$} \\
\hline No & 16 & $6(37.5)$ & $10(62.5)$ & \\
\hline \multicolumn{5}{|c|}{ Had ever used a method or did something to prevent pregnancy } \\
\hline Yes & 209 & $157(75.1)$ & $52(24.9)$ & \multirow[t]{2}{*}{$X^{2}=37.491 ; p<0.001$} \\
\hline No & 177 & $79(44.6)$ & $98(55.4)$ & \\
\hline \multicolumn{5}{|c|}{ Had ever used a family planning method } \\
\hline Yes & 180 & $127(70.6)$ & $53(29.4)$ & \multirow[t]{2}{*}{$X^{2}=12.585 ; p<0.001$} \\
\hline No & 206 & $109(52.9)$ & $97(47.1)$ & \\
\hline \multicolumn{5}{|c|}{ Would accept any help to avoid getting pregnant } \\
\hline Yes & 284 & $179(63.0)$ & $105(37.0)$ & \multirow[t]{2}{*}{$X^{2}=1.613 ; p=0.204$} \\
\hline No & 102 & $57(55.9)$ & $45(44.1)$ & \\
\hline
\end{tabular}


Table 4 Mulitivariate analysis of the determinants of unmet need for contraception

\begin{tabular}{|c|c|c|c|}
\hline Characteristic & Adjusted Odds Ratio & 95\% Confidence Interval & $P$-value \\
\hline \multicolumn{4}{|l|}{ Age group (years) } \\
\hline$<20$ & 0.85 & $0.36-2.02$ & 0.715 \\
\hline $20-24$ & 0.26 & $0.11-0.58$ & 0.001 \\
\hline $25-29$ & 1.00 & & \\
\hline $30-34$ & 1.31 & $0.66-2.59$ & 0.436 \\
\hline $35+$ & 0.25 & $0.09-0.73$ & 0.011 \\
\hline \multicolumn{4}{|l|}{ Education } \\
\hline None & 5.06 & $1.07-24.01$ & 0.041 \\
\hline Primary & 2.74 & $0.44-17.17$ & 0.281 \\
\hline Junior High School & 2.20 & $0.50-9.65$ & 0.295 \\
\hline Senior High School & 2.78 & $0.64-12.01$ & 0.171 \\
\hline Tertiary & 1.00 & & \\
\hline \multicolumn{4}{|l|}{ Ethnicity } \\
\hline Gonja & 1.00 & & \\
\hline Dagomba & 0.45 & $0.20-1.01$ & 0.054 \\
\hline Others & 0.93 & $0.32-2.70$ & 0.887 \\
\hline \multicolumn{4}{|l|}{ Occupation } \\
\hline Farmer & 1.24 & $0.16-9.35$ & 0.834 \\
\hline Trader & 0.56 & $0.09-3.61$ & 0.538 \\
\hline Civil/public servant & 1.00 & & \\
\hline Student & 1.28 & $0.20-8.05$ & 0.796 \\
\hline Unemployed & 0.22 & $0.03-1.64$ & 0.141 \\
\hline Others & 0.79 & $0.10-6.20$ & 0.823 \\
\hline \multicolumn{4}{|c|}{ Awareness on family planning } \\
\hline Yes & 1.00 & & \\
\hline No & 3.93 & $1.12-13.80$ & 0.033 \\
\hline \multicolumn{4}{|c|}{ Had ever used a method or did something to prevent pregnancy } \\
\hline Yes & 1.00 & & \\
\hline No & 1.81 & $1.09-3.00$ & 0.022 \\
\hline
\end{tabular}

educational status. Our finding is consistent with findings from other studies which reveal that women with higher levels of education have better access to information on modern contraceptives and health facilities than those with no or low levels of education and education mediates improved contraceptive usage [13, 21, 30-35]. This means that the use of modern contraceptives in order to minimize fertility, morbidity and mortality in mothers and children is better appreciated by educated women. Also, these women may have better chances to seek appropriate counselling from health workers concerning adverse effects of contraceptives and how to avoid them [26]. Moreover, access to education could increase job/employment opportunities and therefore income earning opportunities which may translate into improved contraceptive access and hence usage [24]. The role of education in improving maternal and child health cannot be overemphasized. In 1995, the government of Ghana launched free compulsory universal basic education [36] and a capitation grant programme was launched in 2005 in which school fees were abolished and public basic schools were to receive a grant of 3 United States dollars per child per academic year [37]. In 2017, a programme was started to absorb the cost of secondary school and vocational training for all students [38]. These efforts are contributing greatly to girl child education and may help improve maternal and child health.

Women who were unaware of FP and women who never used a contraception method nor did anything to prevent pregnancy previously were more likely to have unmet need for contraception. A possible reason for this finding is lack of information on FP or wrong perception about FP hence the unwillingness to adopt it. Some 
studies reported that women perceive FP is for only married couples whilst others hold the believe that it causes injury to the womb $[39,40]$ or makes one barren in future. Thus, FP programmes and educational messages should highlight the benefits of FP and deal with misconceptions women hold concerning it [41].

\section{Limitation of the study}

Information collected relied on recall of events of the women interviewed and may be influenced by recall bias. Younger and unmarried women may under-declare contraceptive use because of the stigma associated with young age or unmarried marital status and sex.

Despite this limitation, this study is of high importance to current research on unmet need for contraception in the district and region and the findings are generalizable to similar districts in Ghana.

\section{Conclusions}

The present study found high prevalence of both awareness on and unmet need for contraception among the study population. Among all the factors studied, age, educational status, awareness on FP and previous use of contraception emerged as determinants of unmet need for contraception in North Gonja District. Educational campaigns to promote contraception should prioritize women of middle age and low educational status. Further studies are needed to understand the low correlation between awareness on and unmet need for contraception.

\section{Supplementary information}

Supplementary information accompanies this paper at https://doi.org/10. 1186/s12905-020-01077-4.

Additional file 1. Questionnaire

\section{Abbreviations}

FP: Family Planning; AOR: Adjusted Odds Ratio; Cl: Confidence Interval

\section{Acknowledgements}

We thank the women of North Gonja who took time off their schedules to respond to the questionnaire.

\section{Authors' contributions}

The study was conceived, designed and implemented by AW. NS, HG, OA and BA supervised data collection. OA and BA entered the data into Stata and prepared it for analysis and NS and HG analysed the data. The manuscript was drafted by OA and BA and critically reviewed by AW. All authors read and approved the final manuscript.

\section{Authors' information}

AW and HG hold PhD and are Senior Lecturer and Lecturer respectively in the School of Allied Health Sciences, University for Development Studies, Tamale, Ghana. NS and BA hold Bachelor's and Master's degrees respectively, and $\mathrm{OA}$ is a candidate for Master's degree.

\section{Funding}

The study was funded by the authors.

\section{Availability of data and materials}

The minimal dataset analysed during the current study can be obtained from the corresponding author upon reasonable request.

\section{Ethics approval and consent to participate}

The protocol for this study (Protocol Number 04-2016) was approved by the Joint Ethics Board of School of Medicine and Health Sciences and School of Allied Health Sciences, University for Development Studies, Tamale. Written informed consent was obtained from the study women and from the parents of subjects less than 16 years old before interviews were conducted. It was made clear to all subjects that participation was voluntary.

Consent for publication

Not applicable.

\section{Competing interests}

The authors declare no competing interests.

Received: 30 September 2019 Accepted: 17 September 2020

Published online: 06 October 2020

\section{References}

1. World Health Organization. Trends in maternal mortality 2000 to 2017: estimates by WHO, UNICEF, UNFPA, World Bank Group and the United Nations Population Division. Geneva: WHO; 2019

2. Whiteford ML. The impact of spina bifida on individuals, families and society. Reprod Toxicol. 2014;48:10

3. Tsui AO, McDonald-Mosley R, Burke AE. Family planning and the burden of unintended pregnancies. Epidemiol Rev. 2010;32(1):152-74.

4. World Health Organization. World health statistics 2016: monitoring health for the SDGs sustainable development goals. Geneva: World Health Organization; 2016.

5. Ahmed S, et al. Maternal deaths averted by contraceptive use: an analysis of 172 countries. Lancet. 2012;380(9837):111-25.

6. Bradley $\mathrm{S}$, et al. Revising unmet need for family planning. DHS analytical studies no. 25. Calverton: 2017, ICF international; 2012.

7. Sedgh $\mathrm{G}$, Singh $\mathrm{S}$, Hussain R. Intended and unintended pregnancies worldwide in 2012 and recent trends. Stud Fam Plan. 2014;45(3):301-14.

8. Darroch JE, Singh S. Trends in contraceptive need and use in developing countries in 2003, 2008, and 2012: an analysis of national surveys. Lancet. 2013;381(9879):1756-62

9. Cleland J, Harbison S, Shah $\mathrm{H}$. Unmet need for contraception: issues and challenges. Stud Fam Plan. 2014;45(2):105-22.

10. GSS, GHS, and ICF Internationa. Ghana Demographic and Health Survey 2014. Rockville: GSS, GHS, and ICF international; 2015.

11. Mosher W, et al. Nonuse of contraception among women at risk of unintended pregnancy in the United States. Contraception. 2015;92(2): 170-6.

12. Krakowiak-Redd D, et al. Family planning in a sub-district near Kumasi, Ghana: side effect fears, unintended pregnancies and misuse of a medication as emergency contraception. Afr J Reprod Health. 2011;15(3): 135-47.

13. Patil, et al. Unmet needs for contraception in married women in a triba area of India. Malaysian J Publ Health Med. 2010;10(2):44-51.

14. Roberts M, Mogan C, Asare JB. An overview of Ghana's mental health system: results from an assessment using the World Health Organization's assessment instrument for mental health systems (WHO-AIMS). Int J Ment Heal Syst. 2014;8(1):16.

15. Staveteig S. Understanding unmet need in Ghana: Results from a follow-up study to the 2014 Ghana Demographic and Health Survey; 2016.

16. Ghana Statistical Service, 2010 population \& housing census report : district analytical report : North Gonja District. 2014

17. Snedecor GWC, William G. Statistical methods; 1989

18. Bongaarts J. United nations department of economic and social affairs, population division world mortality report 2005. Popul Dev Rev. 2006;32(3): 594-6.

19. Nyonator FK, et al. The Ghana community-based health planning and services initiative for scaling up service delivery innovation. Health Policy Plan. 2005;20(1):25-34 
20. Baatiema $L$, et al. Assessing participation in a community-based health planning and services programme in Ghana. BMC Health Serv Res. 2013; 13(1):233.

21. Wulifan JK, et al. A scoping review on determinants of unmet need for family planning among women of reproductive age in low and middle income countries. BMC Womens Health. 2015;16(1):2.

22. Tadele A, Abebaw D, Ali R. Predictors of unmet need for family planning among all women of reproductive age in Ethiopia. Contracept Reprod Med. 2019;4(1):6.

23. Yaya S, Ghose B. Prevalence of unmet need for contraception and its association with unwanted pregnancy among married women in Angola. PLoS One. 2018;13(12):e0209801.

24. Mekonnen W, Worku A. Determinants of low family planning use and high unmet need in Butajira District, south Central Ethiopia. Reprod Health. 2011; 8(1):37.

25. Ali AAA, Okud A. Factors affecting unmet need for family planning in eastern Sudan. BMC Public Health. 2013;13(1):102.

26. Guure $C$, et al. Factors influencing unmet need for family planning among Ghanaian married/union women: a multinomial mixed effects logistic regression modelling approach. Arch Public Health. 2019;77(1):11.

27. Ochako $\mathrm{R}$, et al. Barriers to modern contraceptive methods uptake among young women in Kenya: a qualitative study. BMC Public Health. 2015;15(1): 118.

28. Thummalachetty $\mathrm{N}$, et al. Contraceptive knowledge, perceptions, and concerns among men in Uganda. BMC Public Health. 2017;17(1):792.

29. Thapa S. Unmet need for family planning in Nepal. Nepal Popul Dev J. 1997;(Spec):98-107..

30. Babalola S, Fatusi A. Determinants of use of maternal health services in Nigeria-looking beyond individual and household factors. BMC Pregnancy Childbirth. 2009:9(1):43.

31. Beekle A, McCabe C. Awareness and determinants of family planning practice in Jimma, Ethiopia. Int Nurs Rev. 2006;53(4):269-76.

32. Fantabun M. Comparative study of the characteristics of family planning service users and non-users in Northwest Ethiopia. Afr J Reprod Health. 2006;10(1):62-70.

33. Adetunji JA. Rising popularity of injectable contraceptives in sub-Saharan Africa. Afr Popul Stud. 2011;25(2):587.

34. Blackstone SR. Women's empowerment, household status and contraception use in Ghana. J Biosoc Sci. 2017;49(4):423-34.

35. Nyarko SH. Unintended pregnancy among pregnant women in Ghana: prevalence and predictors. J Pregnancy. 2019;2019:2920491.

36. Ghana Ministry of Education. Free Compulsory Universal Basic Education (FCUBE). Accra: Ministry of Education; 1996.

37. Osei RD, et al. Effects of capitation grant on education outcomes in Ghana. Accra: Institute of Statistical, social and economic research, UG; 2009.

38. Adu-Ababio, K. and R.D. Osei, Effects of an education reform on household poverty and inequality: A microsimulation analysis on the free Senior High School policy in Ghana. 2018, WIDER Working Paper.

39. Meka IA, Okwara EC, Meka AO. Contraception among bankers in an urban community in Lagos state, Nigeria. Pan Afr Med J. 2013;14(1):80.

40. Gebremariam A, Addissie A. Intention to use long acting and permanent contraceptive methods and factors affecting it among married women in Adigrat town, Tigray, northern Ethiopia. Reprod Health. 2014;11(1):24.

41. Apanga PA, Adam MA. Factors influencing the uptake of family planning services in the Talensi District, Ghana. Pan Afr Med J. 2015;20(1):10.

\section{Publisher's Note}

Springer Nature remains neutral with regard to jurisdictional claims in published maps and institutional affiliations.

Ready to submit your research? Choose BMC and benefit from:

- fast, convenient online submission

- thorough peer review by experienced researchers in your field

- rapid publication on acceptance

- support for research data, including large and complex data types

- gold Open Access which fosters wider collaboration and increased citations

- maximum visibility for your research: over $100 \mathrm{M}$ website views per year

At $\mathrm{BMC}$, research is always in progress.

Learn more biomedcentral.com/submissions 